\title{
NOVOS PARADIGMAS PARA O ENSINO E O PLANEJAMENTO DA PAISAGEM
}

\author{
NEW PARADIGMS FOR TEACHING AND PLANNING THE CONTEMPORARY LANDSCAPE
}

\author{
ÁLVARES, Lúcia Capanema \\ PhD, EA-UFMG. E-mail: luciacapanema@terra.com.br \\ TIBO, Geruza L. \\ Especialista, PBH. E-mail: tibo@acesso.com.br
}

SAFE, Simone S.

Especialista.

\section{RESUMO}

As condições de vida nas cidades vêm, desde fins do século XIX, demandando a constante evolução do planejamento e do profissional que o exerce. Este estudo parte da hipótese de descompasso entre a prática profissional do planejador - e a demanda no planejamento da paisagem; seu objetivo é abordar paradigmas do planejamento da paisagem e sua incorporação ao ensino de arquitetura e urbanismo. Analisa as grades curriculares de três cursos de arquitetura e urbanismo em Belo Horizonte, avaliando a formação do profissional para a prática do planejamento. Verificou-se que o ensino aponta algumas diretrizes contemporâneas, mas ainda não é visto como processo - complexo, contínuo e integrado. As recomendações visam formar um profissional crítico, reflexivo e de conhecimento multidisciplinar que contemple as ciências sociais e ambientais, sem o qual não se pode atuar na paisagem urbana da atualidade.

Palavras-chave: Planejamento, paradigmas, sustentabilidade, participação, inclusão, diversidade formal.

\begin{abstract}
The urban conditions of life have, since the XIXth century, posed challenges do the planning profession. This essay looks at the gaps in time between these challenges and the professional responses to urban problems, and in particular the landscape planning responses. Its main objective is to discuss the current and currently shaping paradigms and how they are considered in undergraduate programs. It analyses the curricula of three representative programs in Belo Horizonte, Brasil, evaluating contents and their relationship to contemporary planning needs. Results show that the programs include some important contemporary contents, but present structures badly suited to all-encompassing, process-oriented experiences. Recommendations aim at a critical and reflexive professional, prepared to deal with interdisciplinary issues, concerned with the social sciences and the environment. These qualities seem to be fundamental to responsibly plan the urban contemporary landscape.
\end{abstract}

Key words: Planning paradigms, participation, empowerment, sustainability.

\section{Introdução}

A trajetória do planejamento urbano segue diferentes tendências e modelos - ou paradigmas, fundamentados em categorias e conceitos que caracterizam o pensamento de cada época. No Brasil, o planejamento vive a partir da promulgação da nova constituição, momento singular, em que as políticas urbanas centralizadas no governo federal não mais se aplicam, tornando-se difícil discutir um paradigma dominante: Há inexistência de um pensamento hegemônico. $\bigcirc$ planejamento, porém, ainda não alcança um caráter multidisciplinar, participativo e includente, atendendo somente a demandas pontuais e momentâneas (ÁLVARES, 1992). Seguindo a evolução dos processos de planejamento, das preocupações mundiais no início do século XXI e das 
demandas locais, aponta-se a necessidade de novos paradigmas para a prática profissional e conseqüentemente o ensino.

Objetivos - A intenção é especular se as novas realidades sociais, econômicas, ambientais, culturais e legais vêm sendo incorporadas aos paradigmas de planejamento da paisagem, e se estes são absorvidos na formação acadêmica do arquiteto e urbanista. São objetivos específicos do trabalho: traçar um panorama da evolução dos paradigmas de planejamento, apontar as novas tendências e verificar se os cursos ofertam os conhecimentos necessários para um planejamento atualizado. $O$ artigo parte da hipótese de que há um descompasso entre a prática profissional do planejador arquiteto-urbanista e a demanda real de planejamento que demanda uma evolução paradigmática. $\bigcirc$ objetivo é adicionar evidências no sentido de confirmar esse desencontro.

Metodologia - Para constatar o descompasso entre oferta e demanda profissional, foi necessário explorar em revisão bibliográfica e pesquisa documental suas variáveis mais importantes: A história do planejamento urbano e de seu ensino no País; os paradigmas da multidisciplinaridade, da participação e da inclusão; a pressão pela incorporação da sustentabilidade; a evolução paisagística; as novas pressões de internacionalização das cidades; e a atual formação acadêmica do arquiteto urbanista.

As grades curriculares revelam indícios sobre a futura atuação do profissional no mercado de trabalho. O trabalho enreda-se na busca dos conteúdos propostos na formação do arquiteto e urbanista dos cursos de arquitetura e urbanismo da Escola de Arquitetura e Urbanismo da Universidade Federal de Minas Gerais (EAUFMG), da Pontifícia Universidade Católica de Minas Gerais (PUC Minas), e do Centro Universitário de Belo Horizonte (UNI-BH) em 2004.

A análise dos currículos foi feita a partir das grades curriculares disponibilizadas, ementas das matérias, carga horária e objetivos das instituições educadoras.

\section{Contextualização do planejamento urbano e seu ensino no país}

Segundo Álvares (2001), a evolução de paradigmas do planejamento urbano no mundo segue uma linha evolutiva, acompanhando sua história político-econômica, e pode ser sistematizada em três dimensões: a evolução temática, a evolução processual, e a evolução ideológica: $A$ dimensão temática partiu de um planejamento das questões físico-territoriais, evolviu para englobar um ou outro aspecto social ou econômico, para chegar a um planejamento multidisciplinar. A evolução processual partiu da repressão à participação, quando o planejamento se fazia nos gabinetes sob o comando das elites, evoluindo para um planejamento centralizado e dominado pelos tecno-burocratas que incorporavam algumas demandas da sociedade, apontando finalmente para um planejamento participativo e descentralizado. A terceira dimensão partiu do planejamento concentrador de riquezas, que visava acumular capital nos investimentos industriais, passa por um momento neo-liberal, em que o estado adota uma estratégia de planejamento laissez faire, já apontando para um planejamento inclusivo, de melhor distribuição de riquezas e de empoderamento através da capacitação.

No Brasil, correspondeu à fase colonial, a ausência de planejamento; à República Velha, quando iniciou-se o processo de industrialização, um urbanismo pontual, pouco planejado e elitista; aos governos populistas (1930 a 1964), quando o país se torna urbano e industrializado, um planejamento físico-territorial, centralizado e concentrador; à ditadura militar e à nova república (1964-1988), um planejamento ainda físico-territorial, centralizado, tecno-burocrata e concentrador; e, finalmente, à fase pós-1988, a reorganização das estruturas e processos de planejamento de forma mais democrática e includente. 
A Constituição de 1988 traz a descentralização administrativa e tributária. Sua grande evolução, porém, estaria na inclusão da função social da propriedade, o que possibilitou a elaboração de novos e mais inclusivos instrumentos de política urbana no Estatuto da Cidade, que somente seria aprovado em 2001 (BRASIL, 2001) a partir de propostas elaboradas pela sociedade civil organizada.

O Estatuto da Cidade (Lei n. 10.257 de 2001), regulamenta os artigos 182 e 183 da Constituição Federal e estabelece parâmetros e diretrizes da política urbana no Brasil; amplia o leque de instrumentos de gestão, uso e ocupação do solo com novas preocupações, centradas na gestão democrática, na participação, na descentralização, na inclusão e na cooperação entre os 1으, 2은 e 3 o setores. As principais inovações contidas no Estatuto dizem respeito à relativização do direito de propriedade, à submissão dos planos diretores ao desejo e crivo popular, e à promoção da inclusão e da sustentabilidade ambiental e patrimonial. Já o Plano Diretor, conforme estabelecido pelo Estatuto da Cidade, define a função social do espaço urbano e da propriedade, garantindo o direito de moradia a todos, priorizando os espaços coletivos de suporte à vida, levando-se em conta um sistema municipal de mobilidade e acessibilidade a espaços públicos e privados.

Na análise oferecida por Álvares (1992) pode-se perceber que as variáveis temáticas (físico-territoriais, econômicas e sociais), políticas (descentralização e participação) e humanitárias (distribuição de riquezas e inclusão social) vêem sendo incorporadas ao planejamento em decorrência de pressões reais. É a partir dessa matriz que se pode advogar pela consideração também das variáveis ambientais, formais, e econômico-estruturais no planejamento da paisagem.

A questão ambiental emergente - A partir da década de 1990 a questão ambiental passa a fazer parte das grandes preocupações mundiais e das demandas da sociedade civil organizada. $\bigcirc$ clamor por formas alternativas de gestão ambiental vem tomando corpo no Brasil desde a Eco92, e ganha espaço na medida em que falha o sistema público e se multiplicam os problemas ambientais. Já em 1987, o 7 Simpósio Brasileiro de Recursos Hídricos e Hidrologia e a Carta de Salvador ressaltavam a importância das questões ambientais aliadas à participação da sociedade e à descentralização dos processos decisórios.

Leff (2001), ao definir que "o princípio da sustentabilidade surge no contexto da globalização como a marca de um limite e o sinal que reorienta o processo civilizatório da humanidade" (LEFF, 2001, p.15), reforça a idéia de uma demanda real pela mudança de paradigma quanto à questão ambiental. Victorino (2003) vê a questão ambiental tornando-se um fator determinante na reconfiguração das estruturas governamentais e das relações entre sociedade e natureza e da sociedade consigo mesma. Nessa perspectiva de incorporação da dimensão ambiental às relações sociais, pode-se argumentar que o Estatuto da Cidade, mais nova peça paradigmática no urbanismo brasileiro, considera o planejamento urbano sustentável como a busca da justiça socioambiental mediante instrumentos aplicados nas cidades.

Os paradigmas formais - Do ponto de vista da forma urbana e da paisagem, pode-se chamar a atenção para uma evolução razoavelmente contínua desde os fins da idade média até o Barroco (no aspecto urbanístico) e o Ecletismo (no paisagismo). Enquanto o Barroco se afiliava à exuberância estética e ao monumentalismo, o Ecletismo, de influência anglo-galicista se filiava ao romantismo idílico (MACEDO, 1999). Ambos irão sofrer a grande ruptura moderna, especialmente no Brasil, quando assumirão cores nacionalistas; o urbanismo, ainda próximo à Europa, proporá modelos baseados na tipificação do homem e no funcionalismo ortogonal, embora com alguma liberdade formal; o paisagismo se aproximará das influências dos EUA, fundando uma síntese original e brasileira. Ambos passarão pela ruptura pós-moderna que significará, no urbanismo, a revalorização dos espaços públicos e sua diversidade de usos, a opção por pequenas intervenções, e um léxico mais vasto e complexo de intervenções. No paisagismo significará, além da cenarização, também uma ampliação das possibilidades e linhas projetuais (MACEDO, 1999). Ambas disciplinas trazem ao profissional contemporâneo a demanda por uma flexibilidade formal, uma base cultural e uma adaptabilidade de funções e linguagens inusitada. 
Os paradigmas econômico-estruturais - Novamente partindo da Idade Média e da economia feudal, instituída durante dez séculos, pode-se atentar para uma ruptura a partir do crescimento do mercantilismo, que dará início a um comércio internacional e ao subjugo das colônias. $\bigcirc$ Brasil surge no nascimento da era moderna e permanece como país periférico durante pelo menos quatro séculos; a ruptura causada pelo advento da máquina pouco abalou a ordem econômica mundial. A libertação das colônias em escala planetária e as conseqüentes crises econômicas e sociais na Europa e nos Estados Unidos já no século XX trarão uma nova lógica para a produção e o consumo no mundo, mas ainda não reverterão a ordem centro-periferia.

A nova ruptura parece se iniciar no período pós-Segunda Guerra, quando a hegemonia dos estados é quebrada em favor de organismos multilaterais; são esses organismos que darão vez ao capital apátrida das grandes corporações mundiais na contemporaneidade: Não mais há lugar fora do capital volátil, das transferências financeiras virtuais, da produção globalizada e da informação midiática. A ordem centro-periferia pode enfim ser alterada, dependendo das condições locais. A nova ordem desafia o planejamento urbano a se internacionalizar, valorizando a história e a produção local, enquanto a paisagem deverá se internacionalizar e atrair o capital, sem se tornar o não lugar (YÁZIGI, 2001).

Algumas conseqüências dos novos paradigmas para o planejamento da paisagem são formalmente perceptíveis, conforme demonstram as Figuras 1 a 4.
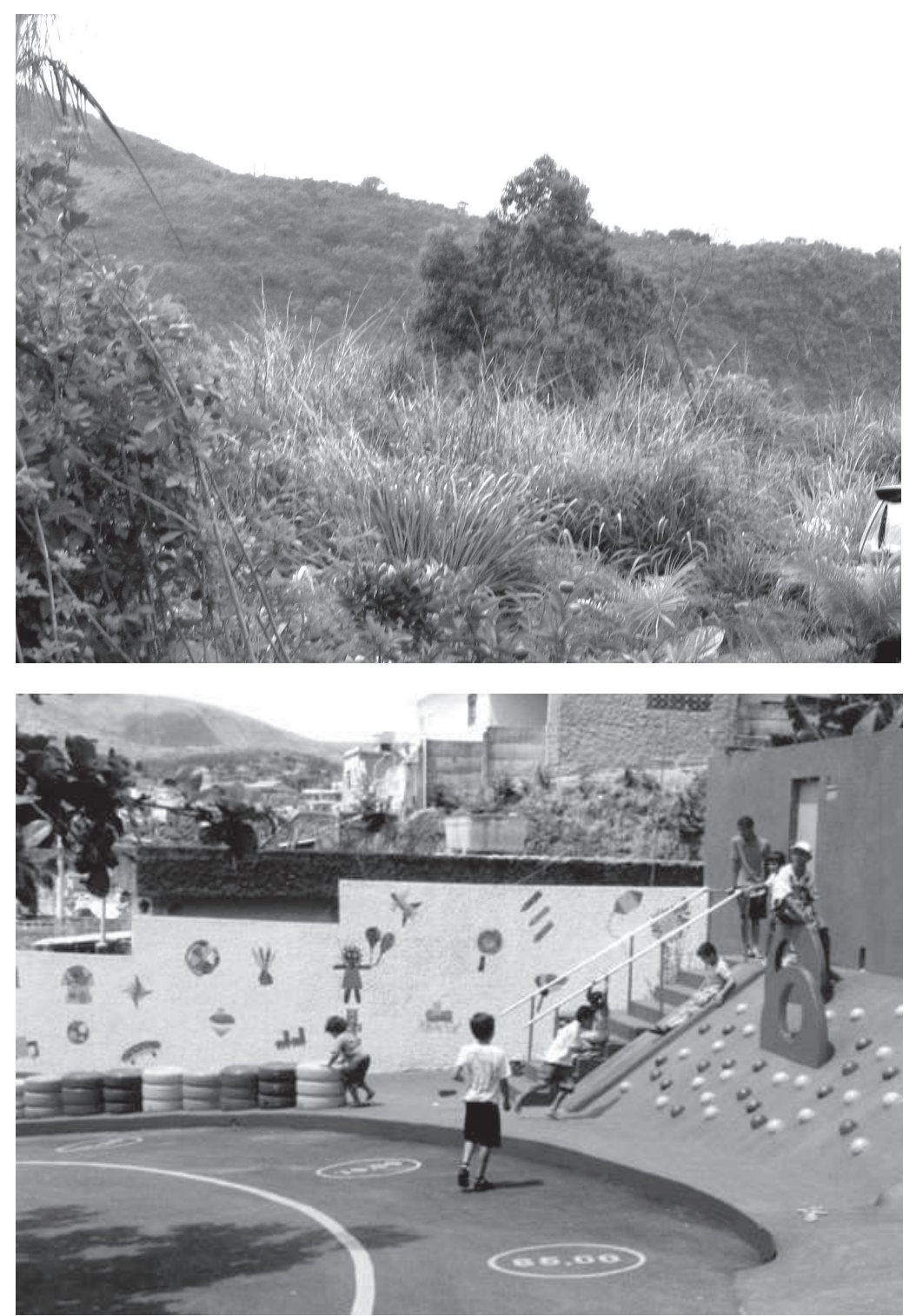

Figura 1: Preservação ambiental em Belo Horizonte

Fonte: Arquivo pessoal

Figura 2: Ampliação do léxico formal e revalorização do espaço público: Pça. Jerimum - Samy Lansky Fonte: Arquivo do arquiteto 


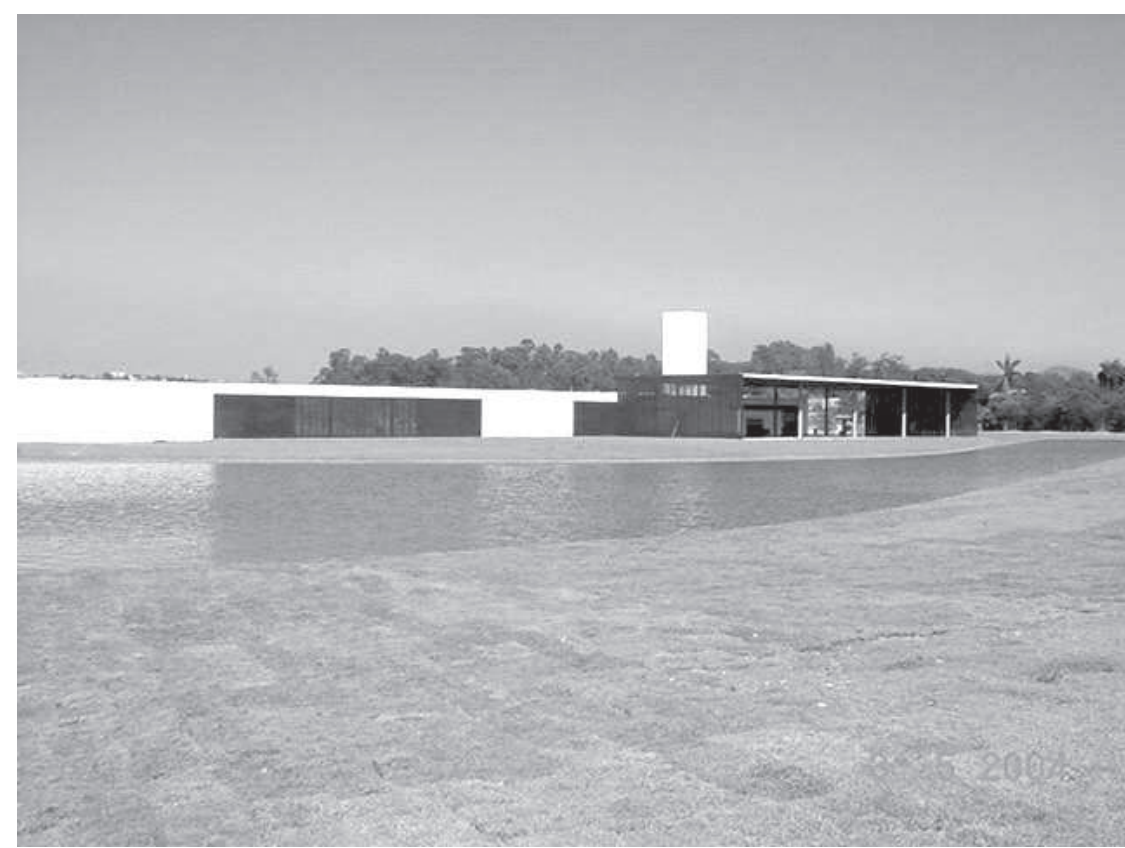

Figura 3: Ampliação do léxico formal e revalorização do espaço público: Pq. Ecológico Francisco L. do Rego - Gustavo Pena

Fonte: Arquivo pessoal

Figura 4: Internacionalização das cidades: Belo Horizonte Fonte: Arquivo pessoal

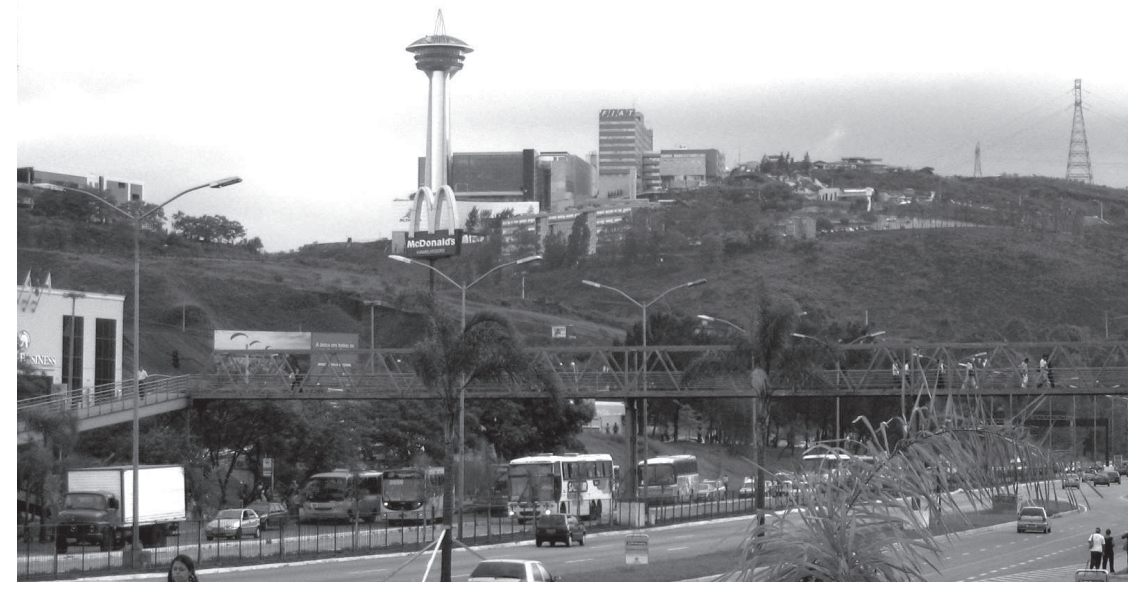

Onsino de Arquitetura e Urbanismo no Brasil - A formação acadêmica do profissional arquiteto urbanista passa por momentos e processos similares aos da própria área de conhecimento.

Segundo Santos (2002), o panorama educacional está organizado em torno de cinco períodos históricos principais: O primeiro, do século XVIII até o início do século XIX; o segundo, da instituição do ensino superior de arquitetura e engenharia no século XIX até 1930 - Se esse período delineou um urbanismo pontual - se muito, não planejado e elitista, mostrou também uma elitização do saber com influência internacional no ensino e nas profissões, especialmente na arquitetura, bem como falta de controle do ensino e da profissão por parte do Estado (SANTOS, 2002).

No terceiro período, entre 1930 e 1960, as poucas tentativas de planejar de modo mais abrangente foram centralizadas. Esta posição centralizadora estabeleceu a maior reforma educacional da história brasileira e criou instituições segundo as exigências da regulamentação profissional; é também marcado pela atuação centralizadora do Estado sobre a profissão e a interferência no ensino de arquitetura, com inclusão e exclusão de conteúdos e criação do sistema Confea/Creas 
tutelado pelo Estado. Nesse período, há também uma transformação do perfil profissional "de arquiteto bel-artista para engenheiro-arquiteto e depois para arquiteto-urbanista" (SANTOS, 2002, p. 16-17). A influência humanista se perdeu na filosofia politécnica que embasava a profissão.

Já no quarto período, da década de 1960 à década de 1980, é marcado pela tutela militar. $\bigcirc$ planejamento centralizado, dominado por técnicos e especialistas influencia também o ensino: a forma metodológica militar de pensar sistematiza o currículo como uma lista de conteúdos, visando formar profissionais técnicos e especializados que atendessem às necessidades do mercado. Nesse período "a área de conhecimento 'Arquitetura e Urbanismo' passou a figurar entre as Ciências Sociais Aplicadas (e não mais entre as Ciências Exatas)" (SANTOS, 2002, p. 17).

No período contemporâneo, a partir do final da década de 1980, percebe-se a intenção do Estado de organizar o planejamento de forma mais descentralizada, democrática, participativa e includente. Assim como foi passada aos municípios e estados a incumbência do planejamento, verifica-se também essa descentralização no âmbito do ensino, mediante a flexibilização curricular, o que fornece certa autonomia às instituições de ensino superior.

A atual formação acadêmica do planejador arquiteto-urbanista - Segundo Apple (1989), é difícil separar as questões educacionais das questões políticas mais amplas: "o currículo não existe como um fato isolado. Ao invés, ele adquire formas sociais particulares que corporificam certos interesses que são [...] resultados de lutas contínuas dentro e entre os grupos dominantes e subordinados". (APPLE, 1989, p. 47-48). O contexto que conforma a realidade do planejamento curricular é tão complexo e interconectado que parece pouco provável um trabalho segmentado.

Paulo Freire já ensinava que o objetivo da educação deve ser a educação dialógica, a práxis em que cada ser humano se reconheça como sujeito holístico, em que educador e educando se libertem uns aos outros na reflexão mediatizada pelo mundo (FREIRE, 2001). A práxis que se deseja inicia-se na educação humanizada, crítica e reflexiva e almeja atingir uma sociedade sustentada nessas bases.

Parâmetros para a formação do planejador contemporâneo - Partindo da demanda por um planejamento multidisciplinar, participativo, inclusivo, sustentável, formalmente diverso e atento às estruturas econômicas, propõem-se os seguintes elementos para a formação do planejador:

- Oferecer disciplinas que tratem de saberes interdisciplinares que permitam sua aplicação prática em trabalhos de campo e em atividades de extensão. Elas devem abordar conteúdos relativos ao desenvolvimento sustentável e à urbanização; às relações econômicas, sociais e culturais; à ética; à gestão pública compartilhada; à participação popular; à inclusão social; aos métodos quantitativos e qualitativos para análise de dados; ao patrimônio ambiental urbano; à diversidade de formas da contemporaneidade; aos impactos ambientais; à infra-estrutura urbana e ao saneamento; ao planejamento de transportes e de trânsito; aos instrumentos de planejamento disponíveis na legislação, à ecologia, à geologia e à geomorfologia; à gestão de bacias hidrográficas; à política habitacional.

- Ampliar a possibilidade da atitude dialógica visando formar um planejador que atue como mediador e educador-educando.

- Ampliar a possibilidade da educação libertadora de Freire, empoderando o cidadão como sujeito na gestão participativa do planejamento.

- Ampliar a capacidade e a qualidade do corpo docente das Instituições de Ensino Superior (IES), como determinantes da forma como as disciplinas serão selecionadas e aplicadas (metodologia).

- Implantar um currículo eficiente - visto como processo contínuo e não fragmentado, capaz de formar um profissional de visão crítica e reflexiva. 


\section{Análise da formação do arquiteto-urbanista em Belo Horizonte}

Observa-se que os cursos de arquitetura e urbanismo em Belo Horizonte funcionam em bases semelhantes, pois se remetem às mesmas instâncias reguladoras profissionais e educacionais e são provenientes da mesma tradição de ensino.

Todas as faculdades apresentam disciplinas referentes a estudos econômicos e panorama político e social, de caráter obrigatório nas diretrizes curriculares; propõem disciplinas que tratam da prática profissional, de administração empresarial aplicada à arquitetura e ao urbanismo, gestão do território e de organizações públicas e privadas. Também abordam a legislação aplicada à profissão, leis de parcelamento, uso e ocupação do solo, código de ética, obras e planos diretores, além de noções de Direito Urbanístico e Ambiental.

Embora essas disciplinas apresentem uma base para as ciências sociais e humanas, essa base não se mostra consistente para uma compreensão interdisciplinar pelo futuro profissional. Os cursos parecem não atentar para a necessidade desse conhecimento e para a complexidade que ele suscita, principalmente no que se refere ao tempo de oferta das disciplinas -30 horas. Nenhum dos três cursos propôs, em seus currículos, disciplinas que abrigassem métodos quantitativos e qualitativos, matéria fundamental para que o planejador estabeleça parâmetros, hipóteses, inter-relações e análise de dados de todas as variáveis do planejamento. Não há ênfase em conteúdos relativos ao desenvolvimento sustentável ou à contextualização político-econômica do planejamento.

Apesar de em alguns casos haver uma abordagem multidisciplinar da cidade e dos trabalhos com a comunidade, não se contextualiza os métodos participativos e inclusivos em contraposição aos métodos clássicos. Há ainda grandes lapsos de tempo no ensino destes conteúdos, o que pode ser prejudicial. Seria justamente a junção continuada de conhecimentos interconectados que capacitaria o estudante para uma atuação transdisciplinar e crítica, a ser rebatida no momento da sua inserção no mercado e na práxis profissional. A dicotomia entre visão fragmentada e visão holística e mais humanizada se encontra presente nas grades curriculares, no sistema de ensino e na maneira de interpretar e atuar profissionalmente.

Verifica-se que a produção de pesquisa no campo da arquitetura e urbanismo não consta como parte do currículo mínimo obrigatório, apesar de alguns cursos oferecerem disciplinas de metodologia de pesquisa. Ressalte-se que essa é uma atribuição legal.

\section{Prática profissional, atribuição e demanda para o planejamento contemporâneo}

A homogeneidade dos currículos desde 1930 não pode ser explicada a pelos mecanismos reguladores do currículo, mas por conveniência. Se o currículo homogêneo seria necessário para garantir padrões de qualidade no ensino, o que parece governar é a manutenção da habilitação profissional única do arquiteto-urbanista em todo o território nacional. A homogeneidade, porém, tem como contraponto a fragmentação das disciplinas, formando um profissional generalista e muitas vezes superficial.

Há uma resistência histórica à incorporação de fato das ciências sociais nos currículos de graduação em Arquitetura e Urbanismo. Um possível motivo é o despreparo específico dos docentes e a não exigência deste saber no momento de admissão dos professores; o arremedo é a incorporação de sociólogos, economistas e outros profissionais aos quadros institucionais. Isso é reconhecer a falha na formação do corpo docente, altamente indesejável, pois contraria as atribuições profissionais.

Os indícios de falhas nos currículos e nos projetos pedagógicos ora adotados, como fragmentação, pouca sistematização e contextualização dos saberes, deficiência da carga horária para 
uma base consistente nas ciências sociais, quase ausência de pesquisa, dentre outras, adicionam evidências à questão central da hipótese: há um descompasso entre o ensino, a prática legal e a demanda da sociedade por um planejador e um planejamento sustentáveis.

Embora o planejamento urbano no Brasil ainda não tenha alcançado caráter multidisciplinar e includente, como já argumentado por vários autores, é chegado o momento de questionar novamente o paradigma vigente, argumentando pela incorporação de conceitos contemporâneos ao planejamento, como a sustentabilidade, a diversidade de formas e a estruturação do desenvolvimento. Para tal, é preciso reformular não só a prática profissional, mas também o ensino que a formata.

\section{Conclusões e recomendações}

artigo discutiu a formação do arquiteto vis-à-vis suas atribuições profissionais e as demandas da sociedade atual. Especulou-se o descompasso entre a demanda real do planejamento, alguns parâmetros para o ensino do planejamento crítico e sustentável e a oferta curricular.

Utilizou-se a revisão bibliográfica e documental, analisando os currículos de três escolas de Arquitetura e Urbanismo de Belo Horizonte. A pesquisa demonstra que a formação acadêmica ainda não é um processo que visa um profissional crítico, reflexivo e de conhecimento multidisciplinar, que contempla as ciências sociais e ambientais para o planejamento sustentável.

Destacado a necessidade da formação de um profissional com conhecimentos abrangentes e que atue de maneira crítica em sua práxis, através de uma metodologia reflexiva, dialógica e que permita a junção da teoria e da prática. Essa questão traz consigo várias necessidades:

- Formação diferenciada do professor, com especial atenção à teoria pedagógica, capacitando-o para a reflexão sobre o processo educacional e o papel do docente (SANTOS, 2002);

- Implementação de um ambiente crítico, que contemple o acesso institucional de professores e alunos a conteúdos interdependentes nas ciências sociais, humanas, da terra, e os jurídicos;

- Definição clara e democrática do perfil do profissional a ser formado afinado com a percepção da realidade, a sociedade e suas demandas, como forma de legitimar a disciplina e seus currículos (SANTOS, 2002);

- Instituição e aplicação da prática do planejamento multidisciplinar, participativo, inclusivo, sustentável, formalmente diverso e atento às estruturas econômicas, durante a formação acadêmica por meio de trabalhos, práticas e disciplinas;

- Alteração de grade curricular para configurá-la como um processo orientado para a formação de sujeitos críticos e autônomos - homens-sujeito, capazes de influenciar os rumos das sociedades locais e de "empoderar" a coletividade, ou seja, fornecer as bases e a possibilidade de experimentação - formadoras da práxis, para que ela se sinta capaz de ser o agente transformador de sua vida.

\section{Bibliografia}

ÁLVARES, Lúcia Capanema. Brazilian metropolises: A planning challenge. 1992. 69 p. Dissertação (Mestrado em Planejamento Urbano e Regional) - Memphis State University, Estados Unidos, 1992.

APPLE, Michael W. Currículo e poder. Educação e realidade. Porto Alegre, v. 14, n. 2, p. 46-57, jul./dez. 1989.

FREIRE, Paulo. Pedagogia do oprimido. 17 ed. Rio de Janeiro: Paz e Terra, 2001.

LEFF, Enrique. Saber ambiental. Sustentabilidade, racionalidade, complexidade, poder. Petropólis: Vozes, 2001.

MACEDO, Silvio S. Quadro do paisagismo no Brasil. São Paulo: Edusp/Coleção Quapá, 1999. 
MELLO, Sandra S. Gestão ambiental urbana dos espaços de margens dos cursos d'água. In: I SEMINÁRIO NACIONAL SOBRE REGENERAÇÃO AMBIENTAL DE CIDADES: ÁGUAS URBANAS. Anais. 2005. 1 CD-ROM.

MMA - MINISTÉRIO DO MEIO AMBIENTE. Agenda 21 Brasileira. Disponível em: <www.mma.gov.br.> Acesso em: 12 mar. 2006.

SANTOS, Roberto Eustáquio. Atrás das grades curriculares: Da fragmentação do currículo de graduação em arquitetura e urbanismo no Brasil. 2002. 225 p. Dissertação (Mestrado em Arquitetura e Urbanismo) - Escola de Arquitetura, Universidade Federal de Minas Gerais. Belo Horizonte, 2002.

VICTORINO, Valério I. P. Monopólio, conflito e participação na gestão dos recursos hídricos. Ambiente \& Sociedade, v. VI, n. 2, jul./dez. 2003.

YÁZIGI, Eduardo. A alma do lugar. 2 ed. São Paulo: Contexto, 2001. 